\title{
Is dermal melasma a phototoxic reaction? A case report
}

\begin{abstract}
Pigmentation related to drugs consist $10-20 \%$ of cases with acquired hyperpigmentation. Melasma is a common acquired disorder characterized by symmetric, hyperpigmented patches with an irregular outline, occurring most commonly on the face. Melasma is rarely seen in males. High ultraviolet exposure and family history are the most common in ethiology and some drugs may result melasma to be seen in males which is very rare. Phototoxic drug reaction should also be considered in differential diagnosis in male patients with hyperpigmentation on the sun exposed areas.
\end{abstract}

Keywords: melasma, photosensitivity, drug reactions, fluoxetine, pigmentation

\author{
Volume 2 Issue 3 - 2018 \\ Yavuz Kayaș,' Banu Yaman, ${ }^{2}$ İlgen Ertam, ${ }^{3}$ \\ Taner Akalın, ${ }^{2}$ İdil Ünal ${ }^{3}$ \\ 'Specialist in Skin and Venereal Diseases, Malatya Education and \\ Research Hospital, Turkey \\ ${ }^{2}$ Department of Pathology, Ege University Faculty of Medicine, \\ Turkey \\ ${ }^{3}$ Department of Dermatology, Ege University Faculty of \\ Medicine, Turkey
}

\begin{abstract}
Correspondence: Yavuz Kayaș, Malatya Education and Research Hospital, Özalper Mah, Turgut Özal Bulvarı No:4, 44330 Yeșilyurt/Malatya, Turkey, Tel +90 4223-2534-38, Email dryavuzkayas@hotmail.com
\end{abstract}

Received: April 04, 2018 | Published: June 29, 2018
Abbrevations: SSRI, serotonin reuptake inhibitors; ANA, antinuclear antibody; SJS, stevens-johnson syndrome; TEN, toxic epidermal necrolysis; AGEP, acute generalised exanthematous pustulosis

\section{Introduction}

Melasma is characterized by irregular hyperpigmented macules located typically on the sun exposed areas like frontal, malar zones, upper lip, cheeks and neck. ${ }^{1}$ Melasma is seen commonly in females. Pregnancy, oral contraceptive usage, sunlight, genetic factors and thyroid autoimmunity may trigger melasma. ${ }^{2}$ Melasma is rarely seen in males. ${ }^{3}$ High ultraviolet exposure and family history are the most common in ethiology and some drugs may result melasma to be seen in males which is very rare. ${ }^{4}$ We present this male case of melasma to point out the importance of drugs in etiology and show that drug reaction caused by selective serotonin reuptake inhibitors (SSRI) may rarely be seen.

\section{Case}

A 38years old male patient referred to our clinic with grey-blue discoloration on the right preauricular region which was started two and a half years ago and spread to whole facial area within one year. Dermatological examination showed diffuse grey-blue discoloration in his forehead, both malar and mental regions (Figure 1). Wood lamp examination confirmed dermal melasma. Patient's history revealed that he had been using fluoxetine which he was still using until 5months ago for his depressive complaints, he had used for 2years and he has sun exposure only in his social and occupational life. No abnormalities were detected in complete blood count, routine urine, biochemistry and thyroid function tests. Antinuclear antibody (ANA) was negative. Since there was a history of drug usage, skin biopsy was planned in order to confirm the diagnosis. Skin biopsy showed epidermal atrophy, single cell necrosis, basal cell degeneration and lymphocyte exocytosis, mononuclear cell infiltration containing perivascular rich melanophages in superficial dermis which is interpreted as phototoxic dermatitis (Figure 2). After stopping fluoxetine discoloration areas has started to decrease.
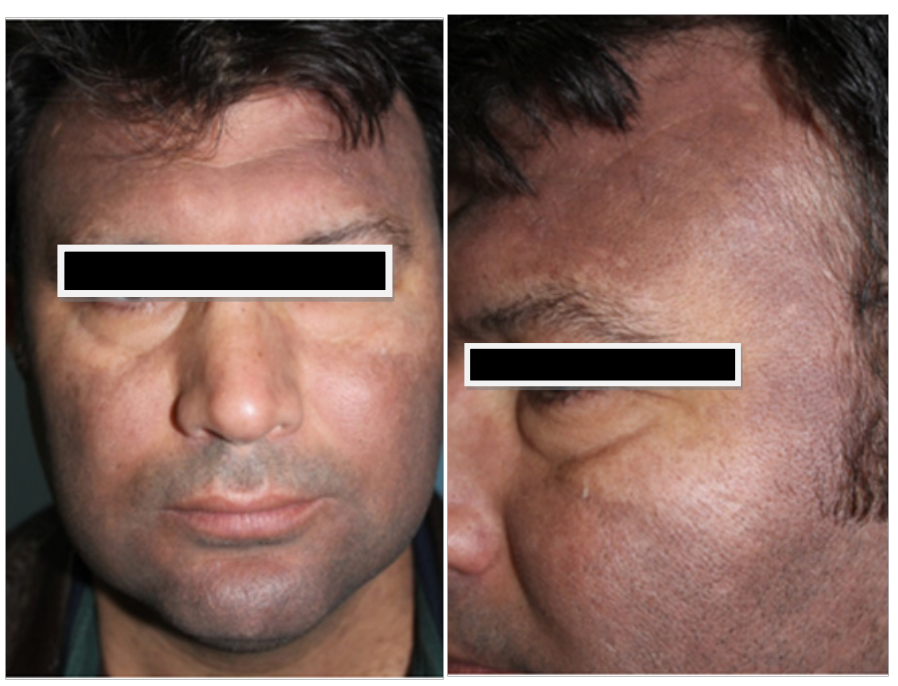

Figure I Grey-blue pigmentation on frontal, malar areas of the patient.

\section{Discussion}

Photosensitive drug eruptions consists $8 \%$ of cutaneous adverse reactions related to drugs. ${ }^{5}$ Pigmentation related to drugs consist 10 $20 \%$ of cases with acquired hyperpigmentation. ${ }^{6}$ Photosensitivity caused by drugs generally occurs with Phototoxicity and photoallergical mechanisms. ${ }^{7}$ Phototoxic skin reactions are usually seen as severe sun burn like, erythema and edema with vesicules and blisters. Skin reactions caused by photoallergical mechanisms are usually seen as polymorphic papulovesicules, itchy eczematous and lichenified lesions. In both types, lesions can be seen as postinflamatuar hyperpigmentation. ${ }^{7,8}$ 


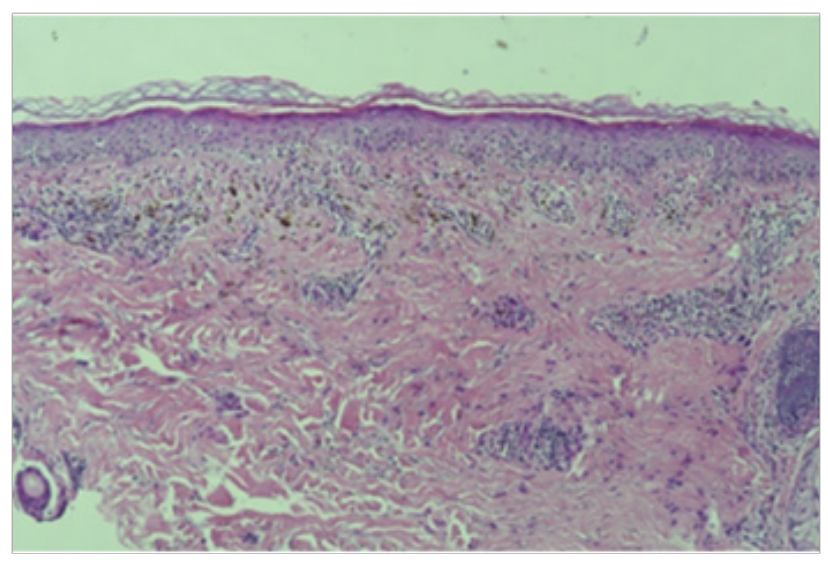

Figure 2A (H\&E x40).

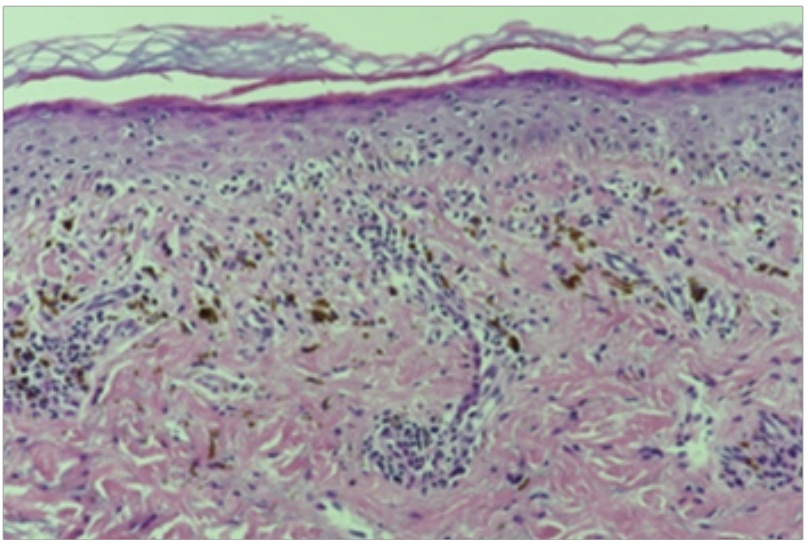

Figure 2B (H\&E x I00).

Figure 2 Epidermal atrophy, single cell necrosis, basal cell degeneration and lymphocyte exocytosis, mononuclear cell infiltration containing perivascular melanophages in superficial dermis.

Skin reactions related to psychotropic drugs are usually associated with antiepileptic drugs. ${ }^{9}$ However, in written literature severe skin reactions like erythema multiform, Stevens-Johnson syndrome (SJS); Lyell's Syndrome (Toxic Epidermal NecrolysisTEN); Acute generalised exanthematous pustulosis (AGEP) caused by antidepressant including SSRIs, erythroderma, tanning, facial erythema, telangiectasia and photo distributed hyperpigmentation caused by only SSRI drugs have been reported. ${ }^{5}$ In one case SJS/ TEN and in another case TEN was reported caused by fluoxetine. In another case hypersensitivity syndrome was reported. ${ }^{9}$ Besides this severe skin reactions in literature photosensitive drug reaction caused by fluoxetine and alprazolame, erythema and edema caused by only fluoxetine was reported. ${ }^{10,11}$

\section{Conclusion}

In our case, diffuse grey-black hyperpigmentation caused by fluoxetine usage was seen and diagnosed with melasma clinically. Wood lamp examination confirmed melasma diagnosis. However, skin punch biopsy intended for differential diagnosis showed findings related to phototoxic dermatitis on this case with drug usage history. Skin findings were uncommon pigmentations rather than erythema, edema, vesicules and blisters. Drug usage history should be evaluated for diagnosis in patients with photo distributed skin findings like melasma. ANA should be evaluated in differential diagnosis for Lupus; photo patch test should be done for ethiological agent and mechanisms. In certain situations urine, blood and faeces tests should be evaluated for porfiria. ${ }^{12}$ Furthermore, widely prescribed psychiatric drugs like SSRIs should be kept in mind as photosensitive drugs and patients should be evaluated for drug reactions and sun protection should be recommended.

\section{Acknowledgments}

None.

\section{Conflict of interest}

There is no conflicts of interest.

\section{Funding}

This study was funded by authors.

\section{References}

1. Chang MW. Disorders of Hyperpigmentation, in Dermatology. In: Jean JV, Bolognia L, Joseph L, editors. $3^{\text {rd }}$ ed, Philadelphia: Elsevier Saunders; 2012. p. 1049-1074.

2. Çakmak SK, Özcan N, Kılıç A, et al. Etiopathogenetic factors, thyroid functions and thyroid autoimmunity in melasma patients. Postepy Dermatol Alergol. 2015;32(5):327-330.

3. Jang YH, Sim JH, Kang HY, et al. The histopathological characteristics of male melasma: Comparison with female melasma and lentigos. $J \mathrm{Am}$ Acad Dermatol. 2012;66(4):642-649.

4. Rashmi S, Garg S. Melasma in Men, in Melasma: A Monograph. In: Sarkar R, editors. $1^{\text {st }}$ ed, New Delhi: Jaypee Brothers Medical Publishers; 2015. p. 80-85.

5. Drucker A, Rosen CF. Drug-induced photosensitivity : culprit durgs, management and preventin. Drug Saf. 2011;34(10):821-837.

6. Dereure O. Drug-induced skin pigmentation. Epidemiology, diagnosis and treatment. Am J Clin Dermatol. 2001;2(4):253-262.

7. Kutlubay Z, Sevim A, Engin B, et al. Photodermatoses, including phototoxic and photoallergic reactions (internal and external). Clin Dermatol. 2014;32(1):73-79.

8. Lehmann P. Photodermatoses, in Braun-Falco's Dermatology. In: Burgdorf W, Plewig G, Wolff HH, editors. $3^{\text {rd }}$ ed, New York: Springer; 2008:573-597.

9. Herstowska M, Komorowska O, Cubała WJ, et al. Severe skin complications in patients treated with antidepressants: a literature review. Postepy dermatol Alergol. 2014;31(2):92-97.

10. Pazzagli L, Banfi R, Borselli G, et al. Photosensitivity reaction to fluoxetine and alprazolam. Pharm World Sci. 1998;20(3):136.

11. Gaufberg E, Ellison JM. Photosensitivity reaction to fluoxetine. $J$ Clin Psychiatry. 1995;56(10):486.

12. I. Drug-induced, I. The, and M. Phototoxic. Evidence-Based Guideline for the Classification and Management of Drug-Induced Phototoxicity. Eur Dermatology Forum Guidel. Photo dermatoses. p. 1-6. 